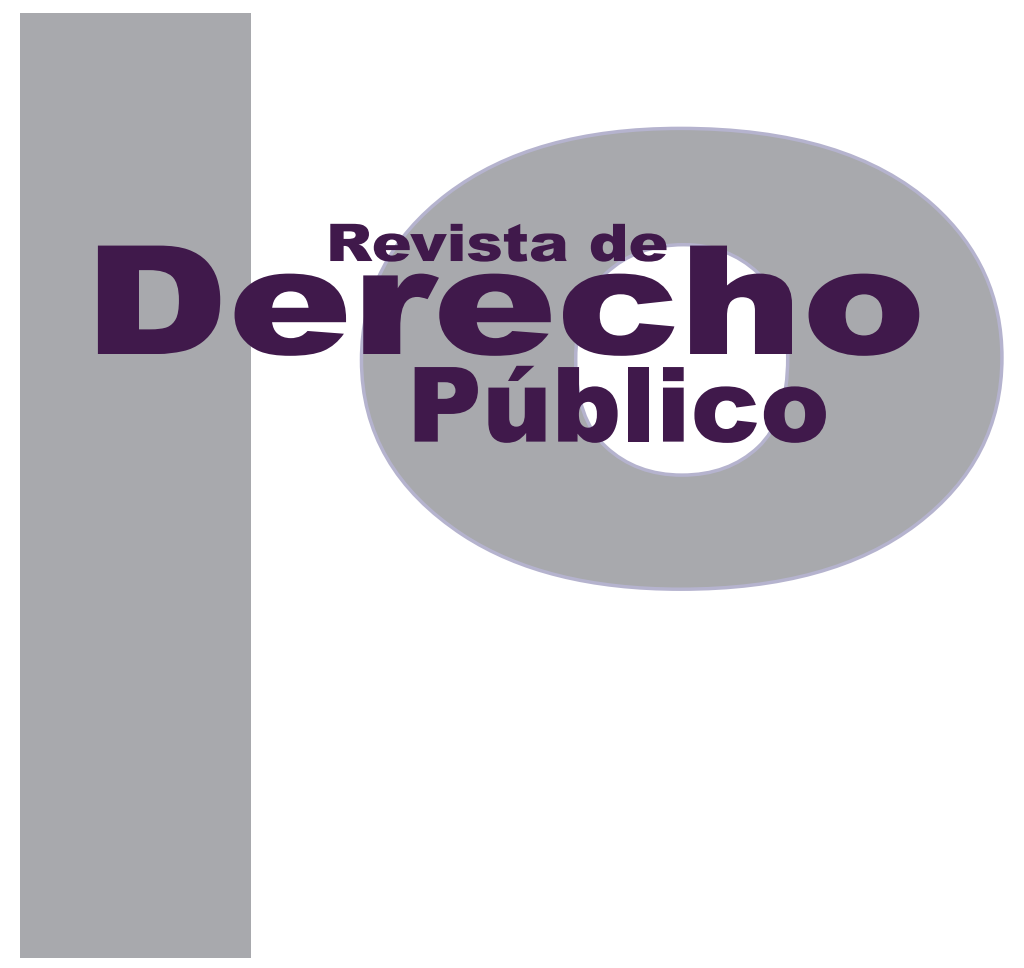

\title{
LA PONDERACIÓN ENTRE LOS CONFLICTOS DE LA LIBERTAD DE EXPRESIÓN Y EL DERECHO A LA VIDA PRIVADA: ESTUDIO JURISPRUDENCIAL ENTRE DOS CULTURAS
}

\author{
DANIEL IVO ODON
}

\author{
Universidad de los Andes \\ Facultad de Derecho \\ Revista de Derecho Público N. ${ }^{\circ} 30$ \\ Enero - Junio de 2013. ISSN 1909-7778
}




\title{
La ponderación entre los conflictos de la libertad de expresión y el derecho a la vida privada: estudio jurisprudencial entre dos culturas
}

\author{
Daniel Ivo Odon*
}

\section{RESUMEN}

A lo largo de la historia de la humanidad la libertad de expresión adquirió un papel central en el ejercicio de la democracia y de las libertades civiles de los ciudadanos. Sin embargo, en el contexto de su coexistencia con otros derechos fundamentales choca eventualmente con otros derechos de naturaleza individual, tal como el derecho a la vida privada. Este trabajo muestra cuál derecho es elegido preponderantemente a través del juicio de ponderación realizado por la doctrina y jurisprudencia de las dos grandes escuelas jurídicas -europea y estadounidenseplanteando así mismo el entendimiento adoptado por la Corte Interamericana de Derechos Humanos.

PALABRAS Clave: derechos humanos, libertad de expresión, vida privada, conflictos, jurisprudencia internacional.

\section{ABSTRACT}

Throughout the history of the mankind, the liberty of expression achieved a huge role in democracy and civil liberties of the citizens. However, into the context of its coexistence with other fundamental rights, it eventually collides with others individual rights, such as the right to a private life. Thus, this work reproduces which right must prevail underneath the balance made by the doctrine and jurisprudence of the two major schools -European and American- to afterwards demonstrate the reasoning adopted by the Interamerican Court of Human Rights.

KEY WORDS: human rights, liberty of expression, private life, conflicts, international case law.

Abogado y profesor de Derecho Público y Teoría del Derecho en la Universidad de Brasilia (UnB), especialista en Derecho Procesal, magíster en Derecho Constitucional y doctorando en Derecho Constitucional en la Universidad de Buenos Aires (UBA). Fiscal General de la Compañía Nacional de Abastecimiento (CONAB) - Brasil. Correo electrónico: odon.daniel@gmail.com. 


\section{SUMARIO}

Introducción - I. UN ABORDAJE DE LA LIBERTAD DE EXPRESIÓN - II. EL ABORDAJE A LA VIDA PRIVADA - III. LOS CASOS EUROPEO Y ESTADOUNIDENSE - IV. LOS PUNTOS DE INTERSECCIÓN ENTRE LAS TRADICIONES EUROPEA Y ESTADOUNIDENSE - V. LA JURISPRUDENCIA DE LA CORTE INTERAMERICANA SOBRE DERECHOS HUMANOS - VI. CONCLUSIÓN - Bibliografía. 


\section{Introducción}

Al final del siglo XVIII ocurrió un despertar de ideales de libertad del ímpetu democrático, tanto en los EE. UU. con la independencia de 1776, la Constitución de 1787 y el Bill of Rights de 1791 como en Europa con la Revolución Francesa y la Declaración de los Derechos del Hombre y del Ciudadano de 1789. En este contexto, la libertad de expresión surgió como medio para proteger al individuo de las intervenciones estatales sobre sus manifestaciones y su vida privada.

En el proceso de internacionalización de los derechos humanos, que ocurrió después de la Segunda Guerra Mundial, la libertad de expresión ocupó un lugar prominente. Todas las Cartas de derechos humanos la contemplan: la Declaración Universal de los Derechos del Hombre de 1948 (artículo 19), la Convención Europea de los Derechos Humanos de 1951 (artículo 10) y la Convención Americana de Derechos Humanos de 1969, también conocida como el Pacto de San José (artículo 13) 1 .

No hay duda de que la libertad de expresión implica cuestiones de diversos matices. Sin embargo, el objetivo de este trabajo es analizar el enfoque adoptado por la jurisprudencia de las Cortes de derechos humanos acerca del conflicto entre libertad de expresión y derecho a la vida privada, profundizado por las dos grandes culturas jurídicas del mundo occidental: los EE. UU. y Europa. A pesar de que los EE. UU. no participaron de la Corte Interamericana de Derechos Humanos, su

1 Está también la Carta Africana sobre los Derechos Humanos y de las Personas de 1981, pero no es significativa para el desarrollo de este trabajo.
Corte Suprema ejerce una función fundamental en la producción de jurisprudencias de vanguardia en el continente y, por eso, examinaremos también sus casos en este trabajo.

Así, los casos que giran en torno a la libertad de expresión desafían los tribunales desde su concepción a finales del siglo XVIII hasta hoy. Entonces, con la globalización y el cambio de la perspectiva de prestaciones de los derechos de sucesivas generaciones -que se contentan con el absentismo estatal y no exigen también la actuación directa del Estado en la implementación y garantía de los derechos- empezamos a mirar no solo al gobierno como invasor de nuestras vidas privadas, sino también a los medios de comunicación. Sin embargo, el Estado tiene la difícil tarea de resolver el conflicto entre dos libertades otorgadas: la libertad de manifestación que autoriza a todos, incluyendo la prensa, a exteriorizar sus pensamientos y opiniones, y el derecho a la privacidad e intimidad ${ }^{2}$.

\section{UN ABORDAJE DE LA LIBERTAD DE EXPRESIÓN}

La imagen tradicional de la libertad de expresión es la de un derecho negativo, que se agota en el deber de abstención del Estado. Esta libertad constituye una limitación para los poderes públicos, erigida para que ellos no tengan cómo impedir o cohibir la manifestación de cualquier pensamiento o idea. Pero, con el avance de la humanidad y la marcha del proceso civilizador, el laissez-faire no parecía suficiente para permi-

\footnotetext{
2 El derecho a la vida privada está en el artículo 8 de la Convención Europea y en el artículo 11 de la Convención Americana.
} 
tir a todos el efectivo ejercicio de esta libertad, hasta que empieza a nacer una relación evidente entre el despliegue de la expresión y el goce de la libertad.

Para el orden público democrático es imprescindible la defensa de la libertad de expresión. El concepto de orden público reclama que, dentro de una sociedad democrática, se garanticen las mayores posibilidades de circulación de noticias, ideas y opiniones, así como el más amplio acceso a la información por parte de la sociedad en su conjunto. La libertad de expresión se inserta en el orden público primario y radical de la democracia, siendo posible afirmar que una sociedad que no está bien informada no puede ser plenamente libre ${ }^{3}$.

La libertad de expresión se encuentra en el ordenamiento estadounidense desde la edición de la $1^{\text {a }}$ Enmienda a la Constitución, en 1791. En particular, después de la Primera Guerra Mundial, la jurisprudencia del Poder Judicial ha buscado expandir y fortalecer la protección al free speech (discurso libre). Hasta hoy, es el más valorizado y salvaguardado derecho fundamental del sistema legal de los EE. UU., siendo considerada una libertad preferencial que tiene un peso superior en la ponderación frente a otros derechos, como la privacidad, reputación, honor e igualdad ${ }^{4}$.

3 Garcia Ramirez, Sergio y Gonza, Alejandra. La libertad de expresión en la jurisprudencia de la Corte Interamericana de Derechos Humanos. San José, CR: Corte Interamericana de Derechos Humanos, 2007, p. 17.

4 Sarmento, Daniel. Livres e Iguais: Estudos de Direito Constitucional. Rio de Janeiro: Lumen Juris, 2006, pp. 265-266.
La tradición estadounidense es libertaria, las personas pueden comunicarse libremente, sin obstrucción del Estado, en un ambiente ideal llamado "mercado de las ideas" 5 . De hecho, si hay defectos en este mercado, aun así es preferible a la intromisión del Estado, cuya conducta tendería a desfavorecer las ideas contrarias a los gobiernos o la mayoría. Diferente a Europa donde hay una tradición más activista, en la que la intervención del Estado es exigida en el ambiente comunicativo de las personas, con la idea de suplir y corregir los desvíos y defectos del mercado de las ideas.

La concepción de la libertad de expresión europea es sustancialmente distinta de la estadounidense en cuanto a la predominancia de la postura del Estado, si libertaria o activista. No se quiere decir con ello que no existe en Europa la visión libertaria y absentista del Estado en la libertad de expresión. Al contrario, ella existe y es valorada, pero aún así impera el valor pujante de la dignidad humana en la sociedad, considerado el más noble de todos los derechos humanos y la base de todas las demás libertades (Tribunal Constitucional Federal Alemán, BVerfGE 7, 198 - Lüth-Urteil) ${ }^{6}$.

Hay un desarrollo en la comprensión de que la libertad de expresión es, antes que nada, un derecho fundamental de defensa contra el Estado, pero ha sido reconocida también su aptitud para generar obligaciones positivas para los

5 Toller, Fernando M. El formalismo en la libertad de expresión: crítica de la distinción absoluta entre restricciones previas y responsabilidades ulteriores. Buenos Aires: Marcial Pons Argentina, 2011, p. 18.

6 Schwabe, Jürgen (org.), Cinquenta Anos de Jurisprudência do Tribunal Constitucional Federal Alemão. Montevideo, Uruguay: Fundación Konrad-Adenauer-Stiftung E. V., 2005, pp. 381-395. 
poderes públicos. Esta libertad no solo limita el comportamiento estatal, sino que también empuja y orienta la acción del Estado que, más allá del deber de abstenerse de su violación, incluye la obligación de promoverla concretamente, inclusive en el campo privado.

En el mundo contemporáneo, por lo tanto, hay una confluencia en las prestaciones negativas y positivas del Estado, pues la libertad de expresión resguarda, tanto los valores sociales como los individuales. Así, para la garantía de esta libertad, el Estado debe hacer un balance entre los conflictos de interés: el free speech -el valor de la libertad de expresión versus la interferencia estatal para cohibir los abusos- y los contravalores ${ }^{7}$. El deber del Estado de regular el ejercicio de la libertad, para ser legítimo, debe estar basado en los valores sociales que justifican la restricción al ejercicio del derecho en el conflicto valor vs. contravalor.

Actualmente hay diversos contravalores escudriñados por los Estados y las Cortes internacionales de los derechos humanos, todos abrigados en las Constituciones y Convenciones internacionales. Son contravalores aceptados por la jurisprudencia: la seguridad pública, la protección de los derechos y libertad de los demás individuos, la protección a la salud, la moral y el orden. Para este trabajo, en particular, se destaca la tendencia europea a salvaguardar el derecho individual a la privacidad, la reputación y el honor.

7 Fiss, Owen M., The Irony of Free Speech. Cambridge, Massachusetts: Harvard University Press, 1996, pp. 05-09.

8 GREeR, Steven. Les exceptions aux articles 8 à 11 de la Convention Européenne des Droits de l'Homme. Strasbourg: Council of Europe

\section{EL ABORDAJE A LA VIDA PRIVADA}

Los derechos humanos se involucran con la historia de la propia humanidad, llevando a cabo todos los rasgos existenciales que, a lo largo del tiempo, ayudan en la valoración y gradación de aquellos más importantes y esenciales al ser humano ${ }^{9}$. En este contexto, no tenemos duda, la privacidad se configura como una de las manifestaciones humanas más valiosa y suprema, ya que es el núcleo de lo que hace la vida interesante. Sin privacidad perdemos nuestra integridad como persona, sobre todo en el contexto de la evolución de nuestra sociedad moderna, con todos sus avances tecnológicos en la vigilancia y la persecución. La invasión de la privacidad es un insulto a nuestra humanidad.

La dificultad actual de conceptuar con precisión la privacidad resulta de la diversidad cultural del planeta. La comprensión de privacidad cambia sustancialmente de una sociedad a otra y esto representa un obstáculo para su dimensionamiento. Sin embargo, nos ocuparemos de dos grandes ejes conceptuales, el estadounidense y el europeo, para luego identificar a cuál nos acercamos más, pues el derecho a la vida privada, constante en todos los instrumentos internacionales de derecho humanos - artículo 8 de la Convención Europea de Derechos Humanos y artículo 11 de la Convención Americana sobre Derechos Humanos-, se aborda de manera distinta.

Publishing, 1997, p. 06.

9 Por esta razón algunos autores prefieren llamarlos "derechos existenciales" en vez de "derechos humanos". Ejemplo, RaBINOVICH-BERKMAN, Ricardo, Derechos humanos: una introducción a su naturaleza y a su historia, Buenos Aires: Quorum, 2007, p. 17. 
Sin embargo, el núcleo comprensible de la vida privada de nuestra modernidad dirige su atención a la interioridad e intimidad de los hombres. Como enseña Urioste Braga, el pensamiento moderno supone esa vuelta a la atención hacia el individuo, hacia su pensamiento, a sus modalidades subjetivas y la historia que habita en su interior; y este mundo interior, a su vez, reclamó un espacio diferente del espacio comunitario, haciendo surgir un derecho de la personalidad humana con dimensiones espaciales análogas a la propiedad privada y con medios de protección también semejantes ${ }^{10}$.

La sociedad europea, por complejas razones históricas, valoriza más la dignidad humana y defiende que cualquier persona, rica o pobre, repugnante o no, tiene derecho a su dignidad y a la exigencia de que la respeten. Esta dignidad, que en un cierto momento histórico perteneció solo a la aristocracia, hoy, en la era de la democracia, pertenece a todos indiscriminadamente $^{11}$. Los EE. UU., al contrario, tienen una historia y tradición muy diferentes y, con ello, también sus razonamientos sobre sus valores. Mientras en Europa la dignidad nació en la aristocracia y "bajó" a los estratos sociales inferiores, en los EE. UU. la comprensión de la dignidad surgió de abajo, -finalmente todos estaban colonizados y subyugados por un poder opresor-y alcanzó el nivel de la sociedad entera, libre y democrática con la independencia en $1776^{12}$.

10 Braga, Fernando Urioste. Libertad de expresión y derechos Humanos. Buenos Aires, Argentina: Editorial IBdeF, 2008, pp. 177-178.

11 Whitman, James Q. Enforcing Civility and Respect: Three Societies. 109 Yale Law Journal 1280, 2000, p. 1283.

Friedman, Lawrence et Arold, Nina-Louisa. Cannibal Rights: A Note on
Entonces, la producción de la norma jurídica se desarrolló, en cada lugar, de acuerdo con su trayectoria histórica y cultural. Los europeos heredaron la supremacía de la dignidad de la nobleza, que fue ampliada cuando la burguesía ganó su espacio social bajo al lema de la igualdad y todos los ciudadanos europeos se tornaron dueños de los mismos derechos. Los estadounidenses, en cambio, construyeron su propia visión de la dignidad que, en su lastre histórico, fue un mero coadyuvante de las libertades conquistadas en el proceso de independencia y, a su vez, representa valores vitales de una sociedad que se ha forjado libre y democráticamente a través de la lucha.

Así, las intuiciones acerca de la privacidad se desarrollan dentro de una esfera de valores jurídicos y sociales presentes en todas las sociedades de acuerdo con su historia y su cultura. Estas intuiciones son acogidas por los tribunales, de ahí que tiendan a reflejar el conocimiento y el compromiso de la sociedad con la base jurídica de los valores de cada cultura. Para eso, debemos distinguir dos connotaciones acerca de la privacidad: a) privacidad como un rasgo de la dignidad, luego, inalienable e indisponible en el mercado privado; y b) privacidad como una acepción de la libertad y, con ello, vista como un bien alienable y disponible en las reglas del libre mercado, susceptible de transacciones comerciales como un derecho de propiedad de su dueño ${ }^{13}$.

the Modern Law of Privacy. Northwestern Interdisciplinary Law Review, vol. IV, nI, 2011, p. 240.

13 LeDESma, Héctor Faúndez. La libertad de expresión y la protección del honor y la reputación de las personas en una sociedad democrática. En Memoria del seminario El Sistema Interamericano de Protección de 
La privacidad como dignidad personal se relaciona con el derecho a la imagen, al nombre y la reputación, es decir, con el control de la imagen pública de la persona y su protección contra la exposición pública involuntaria (ridiculización o humillación $)^{14}$. Por otro lado, la privacidad como libertad comprende básicamente el derecho de libertad contra el Estado, sobre todo con relación a la santidad e inviolabilidad del hogar ${ }^{15}$. Así, para cada una de las acepciones, los grandes villanos son la prensa y el gobierno, respectivamente. Por lo tanto, con respecto a la violación de la privacidad, la cultura europea se centra principalmente en el primer sentido (privacidad como dignidad) y la estadounidense en el segundo (privacidad como libertad), cada una con su propia jurisprudencia.

Esa diferencia, sin embargo, no es absoluta. Ambas culturas son muy complejas y comparten sus influencias mutuas, con lo cual enriquecen la aplicación del derecho. El derecho a la privacidad de los estadounidenses es como un cuerpo inserto en la órbita gravitacional de la libertad, mientras que para los europeos el cuerpo gravita en la órbita de la dignidad, pero hay ciertos momentos en que los dos cuerpos de derecho se aproximan entre sí de manera íntima ${ }^{16}$ como,

Ios Derechos Humanos en el Umbral del Siglo XXI. Tomo I. $2^{a}$ edición. San José, CR: Corte Interamericana de Derechos Humanos, 2003, pp. 559-560.

14 Garcia Ramírez, Sergio et Gonza, Alejandra. La libertad de expresión en la jurisprudencia de la Corte Interamericana de Derechos Humanos. San José, CR: Corte Interamericana de Derechos Humanos, 2007, p. 50 .

15 LEWIS, Anthony. Freedom for Thought that we hate: a biography of the first amendment. New York: MJF Books, 2007, pp. 12-13.

16 Whitman, James Q. The Two Western Cultures of Privacy: Dignity versus Liberty. The Yale Law Journal, vol. 113:1151, 2004, p. 1163. por ejemplo, la importancia de la dignidad y el respeto interpersonal con las minorías, pues las leyes de los EE. UU. son enérgicas en rechazar el uso del discurso del odio (hate speech), en protección de la autoestima de ellos ${ }^{17}$.

En la actualidad, la legislación y la jurisprudencia sobre protección de la vida privada es parte de ambos continentes, manteniendo cada uno sus rasgos propios. Las leyes estadounidenses son mucho menos represivas que las leyes europeas, porque adoptan la tradición libertaria del free speech que muy raramente sufre intervención del Estado en la protección del individuo cuya dignidad fuera atacada. Al contrario, la tradición activista europea exige del Estado la debida interferencia en el uso abusivo de la libertad de expresión por el particular o el gobierno, pues las leyes son de protección de la dignidad humana que, en este aspecto, derogan la supremacía de la libertad.

\section{LOS CASOS EUROPEO Y ESTADOUNIDENSE}

En 1867, el famoso autor francés Alexandre Dumas estuvo implicado con una actriz americana de 32 años, Adah Isaacs Menken. Durante el affaire, ellos tenían la costumbre de sacar fotos "calientes", incluyendo algunas con Adah en trajes íntimos, sola o en pose con Dumas. Cierta vez, Dumas llamó un fotógrafo profesional para que sacara las fotos, pero no hubo ningún acuerdo previo sobre el destino de estas. Así, el

17 Boggs, Danny J. Challenges to the Rule of Law: or, Quod Licet Jovi Non Licet Bovi. In CATO Supreme Court Review 2006-2007. Washington, DC: Cato Institute, 2007, p. 12. 
fotógrafo, en búsqueda de éxito personal, publicó las fotos como su propiedad intelectual. Ellas salieron al mercado y provocaron un escándalo internacional. Por ello, Dumas demandó al fotógrafo ante la justicia, en plena década de 1860.

La pelea, entonces, se planteaba entre la libertad de expresión artística y la propiedad intelectual del fotógrafo, que legítimamente ejerció su derecho sobre su propiedad (las fotos), contra el derecho a la vida privada de Dumas. En aquel momento, el derecho a la propiedad tenía un carácter sagrado (obtenido en la Revolución Francesa) y, por otra parte, las fotos fueron tomadas con el consentimiento de Dumas. Sin embargo, el Tribunal de Apelación de París desafió el derecho supremo de la propiedad con base en el derecho a la vida privada. Aunque una persona haya tácitamente aceptado la publicación de fotografías comprometedoras, mantiene el derecho de retirar su consentimiento. "La publicación de estas fotos puede poner a una persona en evidencia de tal manera que se reflejen en el cuidado de su dignidad y, por lo tanto, le recuerdo que la vida privada debe ser protegida en favor de los intereses individuales y también de la moral"18. Sobre esta base, el Tribunal ordenó que el fotógrafo vendiese su derecho de propiedad sobre las fotos a Dumas.

Después del caso de Alexander Dumas, el derecho europeo luchó por muchos años contra la idea de que alguien pueda vender su dignidad de una forma definitiva, o sea, con la idea mercantilista de la privacidad, muy común en la

18 Whitman, James Q. The Two Western Cultures of Privacy: Dignity versus Liberty. The Yale Law Journal, vol. 113:1151, 2004, pp. 1175-1176. tradición libertaria que la mira como un mero derecho de propiedad. Para ellos, cada uno debe tener el control sobre su imagen, principalmente la desnudez. Si hay arrepentimiento, permanece el derecho de la persona de retirar las imágenes de circulación, aunque la práctica actual muestra la imposibilidad de hacerlo cuando la imagen circula en internet.

La dignidad debe ser considerada de manera distinta a la propiedad. Para la doctrina de los EE. UU., la desnudez vendida es de libre disponibilidad de su propietario y eso no se descarta. El eje de la diferencia entre la doctrina estadounidense y la europea habita en esta premisa, porque la propiedad es de libre disponibilidad de su propietario, mientras que la dignidad no lo es. Para los estadounidenses, la protección de la vida privada tiene su núcleo en la protección del hogar, cuya interpretación actual se ha ampliado más allá de su significado literal. Pero, asimismo, la protección de la vida privada americana pierde fuerza en la medida que la persona afectada va progresivamente alejándose de su casa y empieza a entrar en el campo de la expectativa razonable de privacidad (reasonable expectation of privacy $)^{19}$, o sea, cuanto más lejos de casa, menos la razonabilidad de los juzgadores irá a observar la intimidad y recato del individuo, cuyas expectativas por este tipo de protección judicial deben quedarse igualmente bajas.

Un ejemplo muy claro del desarrollo de la jurisprudencia americana fue el caso de Oliver

19 HALL, Kermit L. The Oxford Companion to the Supreme Court of the United States, $2^{\text {nd }}$ Edition, New York, NY: Oxford University Press, 2005, pp. 783-784. 
Sipple, en 1984. Sipple se convirtió en figura de conocimiento público cuando frustró un intento de asesinato al presidente Gerald Ford en Ios Estados Unidos. Su postura heroica le valió la fama pública que, por desgracia, reveló su orientación sexual por la homosexualidad que, hasta aquel momento, era secreta. A pesar de su disgusto por esta invasión a su vida privada, no podía hacer nada porque en aquel sistema democrático se reconocía la legitimidad de la publicación de los actos privados de una figura pública, basada en la libertad de expresión de la Primera Enmienda de la Constitución de los EE. UU. Sipple intentó numerosas veces extraer la información sobre su homosexualidad de los medios de comunicación pero no lo consiguió y, por eso, se suicidó en 1989, a la edad de 47 años ${ }^{20}$.

Si Sipple hubiera sido europeo esta situación podría haber sido diferente. Aunque la legislación y jurisprudencia actual de Europa autoriza la libertad de expresión sobre figuras públicas, prevalece la protección del honor y la dignidad. Hubo un caso similar, juzgado en Francia en 1985: un ciudadano que participó en el Desfile Gay en París estaba vestido de una manera tan peculiar y extravagante que no solo llamó la atención de los medios de comunicación, sino que estos capturaron su imagen en varias fotos que fueron más tarde publicadas en la prensa. La divulgación ocurrió sin consentimiento de él. Cuando este ciudadano miró su imagen en los diarios y revistas demandó a la prensa. En

20 Sipple v. Chronicle Publishing Co. (1984) 154 Cal.App.3d 1040, en Strahilevitz, Lior Jacob. A Social Networks Theory of Privacy. In Chicago John M. Olin Law \& Economics Working Paper $n^{\circ} 230,2^{\text {nd }}$ Series, November 2004. el juicio se estableció que, el hecho de asistir a un evento público y no ocultar su orientación sexual, no quiere decir que haya perdido su protección contra la mayor audiencia alcanzada por los medios de comunicación. Se confirmó, por tanto, su derecho de personalidad y dignidad en oposición a la publicación desautorizada e inadvertida de su imagen ${ }^{21}$.

Esa comprensión reducida de privacidad en EE. UU. no es algo nuevo, puesto que tiene una larga historia. Podemos decir que para nuestro objetivo, esa historia empezó en 1940 cuando se discutió hasta qué momento las personas pueden mantener su privacidad ajena a los demás. En Sidis v. F-R Publishing Corporation ${ }^{22}$, tenemos la historia de William James Sidis, un ciudadano americano que nació en 1898 y fue considerado un genio por su padre, quien lo sometió a métodos forzados y riguroso estudio durante la infancia. A los dieciocho meses de edad, Sidis ya leía el New York Times. Con este logro notable, su padre informó el hecho a la prensa haciendo famoso a su hijo. A los once años de edad se fue a Harvard y a raíz de ello se transmitió en los medios de comunicación, que él era resultado de un exitoso experimento científico de estudios forzados. A continuación, Sidis se rebeló contra la fama y desapareció de la luz pública, eligiendo vivir en el anonimato. Escapó de los ojos de la prensa hasta 1937, cuando la revista The New Yorker lo encontró y publicó un artículo ofensivo en que lo ridiculizaba porque el

21 CoUNSEIL DE L'EUROPE, ECHR. La liberté d'expression en Europe - Jurisprudence relative à l'article 10 de la Convention Européenne des Droits de l'Homme. Strasbourg: Council of Europe Publishing, 2007.

$22 \quad 311$ U.S. $711(1940)$. 
gran genio no se había convertido en nada significativo para la sociedad, sino en un simple trabajador. A pesar de su derecho a la privacidad, la Corte Suprema de los EE. UU. entendió que Sidis era una figura pública y por eso sus actos de la vida privada podrían ser publicados en los medios de comunicación. Tal cual se desarrolló con Oliver Sipple.

Solamente el juez Brandeis, miembro de la Corte Suprema, en aquel tiempo afirmaba que en el ámbito de la vida privada, el derecho más valioso es el derecho a la privacidad. Los padres fundadores, decía él, han reconocido la importancia de la naturaleza espiritual del hombre, sus sentimientos e inteligencia. Ellos sabían que solo una parte del dolor, el placer y las satisfacciones de la vida están ligados a las cosas materialesy preveían la protección de los estadounidenses en sus creencias, pensamientos, emociones y sensaciones. Esto le permitió al juez Brandeis llegar a la conclusión de que el derecho a la tranquilidad, de ser dejado solo, es el más comprensible de los derechos y el derecho más valioso en una sociedad de hombres civilizados $^{23}$. A pesar de su entendimiento aislado, la Corte de los EE. UU. siempre dio predominio a los medios de comunicación y su libertad de expresión ${ }^{24}$.

23

24 Sin embargo, existen actualmente cuatro excepciones a esa regla, todas construidas por la jurisprudencia de la Corte Suprema. Son las llamadas branches of privacy law: (i) el uso de doble (appropriation of the name or likeness of another), como ocurrió con Jaqueline Kennedy Onassis que demandó a las empresas que contrataron a la modelo Barbara Reynolds para que el público pensara que era Jaqueline y ganó el proceso; lo mismo ocurrió con Woody Allen vs. las empresas que contrataron su doble, Phil Boroff; (ii) intrusión por aislamiento (intrusion upon seclusion), debatido en el caso Snyder v. Phelps et al, 562 U.S. _ (2011); (iii) publicidad de los hechos de la vida privada que no son de interés público (public disclosure of private facts not of legi-
En el choque entre la privacidad y la libertad de expresión en los EE. UU., a pesar de los dos estar protegidos por las leyes, la privacidad casi siempre pierde. Los estadounidenses predican la libertad para discutir y descubrir los secretos de sus vecinos, celebridades y autoridades públicas; esperan que el gobierno conduzca sus negocios públicamente y en especial esperan que los medios de comunicación descubran y revelen la verdad, no solo la verdad sobre el gobierno y los asuntos de interés público, sino la verdad acerca de las personas ${ }^{25}$. En la doctrina estadounidense, el individuo tiene derecho personal sobre su imagen y puede demandar a quien indebidamente la usurpe o haga uso de ella. Pero, al mismo tiempo, es cierta la comprensión de que la imagen de alguien es una parte de su acervo patrimonial y funciona como un commodity comercial. Si la imagen pertenece al individuo entonces es su propiedad y, por lo tanto, podrá venderla o negociarla.

Al contrario, en Europa, el honor y la dignidad de la persona casi siempre vence en el choque entre la privacidad y la libertad de expresión. Básicamente, la diferencia refleja la historia cultural de cada país. Mientras para Goethe el desarrollo de la personalidad humana es una gran bendición para un niño en la tierra, para Jefferson la libertad de expresión es indispensable para

timate concern to the public), su enfoque son los hechos de la gente común, no los de las figuras públicas y celebridades, como en el caso Shulman v. Group W Productions Inc., 18 Cal. 4th 200 (1998); y, (iv) el falso foco de la vida privada (disclosure of private facts in such a way as to portray victims in a false light), que trata de la publicidad de la vida privada cuya evidencia se muestra falsa, como en el caso Time, Inc. v. Hill, 385 U.S. 374 (1967).

25 Anderson, David A. The Failure of American Privacy Law. In Protecting Privacy, Basil S Markesinis ed., 1999, p. 140. 
la fundación de una sociedad libre ${ }^{26}$. Para los europeos, los estadounidenses no entienden lo que realmente significa el derecho a la privacidad.

En 2011, la Corte Europea de Derechos Humanos juzgó el caso de Max Mosley sobre el predominio de su privacidad ${ }^{27}$. Hijo de Sir Oswald Mosley, una figura muy famosa en la sociedad inglesa por ser un gran líder fascista, Max también es famoso porque es parte de la organización del campeonato de Fórmula Uno en Inglaterra. Ocurrió que un tabloide británico publicó fotografías y videos que exponían a Max Mosley conduciendo una sesión de sexo sadomasoquista con prostitutas, en un departamento en Chelsea. Esa historia fue un éxito sensacionalista para la prensa, pero Mosley demandó al tabloide por invasión de su vida privada. No hay duda que la Corte confirmó el derecho de Mosley. Los jueces hicieron la distinción entre interés público y lo que interesa al público. A pesar de que al público le gusta conocer la vida íntima de Mosley, se entendió que esa intrusión de la prensa fue infundada. Se ha dicho que el público tiene el derecho de conocer los hechos, pero solamente si existe una razón legítima para ello, es decir, que la curiosidad, entretenimiento e interés lascivo no son excusas válidas. En este sentido, vence la dignidad del fuero interno de los hombres, donde se esconden las intimidades y secretos de la vida privada, que deben ser respetados por el prójimo, la sociedad y el Estado.

\footnotetext{
26 Whitman, James Q. The Two Western Cultures of Privacy: Dignity versus Liberty. The Yale Law Journal, vol. 113:1151, 2004, p. 1198.

27 Mosley v. United Kingdom, Application n. 48009/08, juzgado el 10 de mayo de 2011, en la Corte Europea de Derechos Humanos.
}

Mucho más que el respeto a la vida privada, ese ejercicio de ponderación a favor de la dignidad humana se traduce en la protección de la moral europea, concepción que cambia de lugar a lugar y de tiempo en tiempo, sobre todo en nuestra época, caracterizada por la velocidad y el alcance de la evolución de las opiniones y pensamientos. Lo que ocurre es que, a pesar del énfasis y la importancia de la libertad de expresión en la sociedad democrática moderna, la tendencia jurisprudencial sigue en el sentido del mantenimiento de la restricción de la libertad basada en la protección de la moral, sobre todo cuando se trata de la naturaleza sexual, lo que no sucede cuando el tema es el gobierno y sus políticas ${ }^{28}$.

\section{LOS PUNTOS DE INTERSECCIÓN ENTRE LAS TRADICIONES EUROPEA Y ESTADOUNIDENSE}

Como se ha indicado, las doctrinas no son absolutas, al contrario, a veces intercambian experiencias entre sí. En algunos momentos veremos la jurisprudencia estadounidense exaltando la privacidad y el honor del individuo, del mismo modo que la jurisprudencia europea autorizará la publicación de actos de la vida privada sin observar el derecho de la persona involucrada. Pero tenemos que resaltar que esos casos constituyen excepciones a las reglas y orientaciones jurídicas mencionadas arriba, pues las circunstancias sociales de cada caso autorizan ese grado de oscilación, de modo que el resultado final

\footnotetext{
28 GREER, Steven. Les exceptions aux articles 8 à 11 de la Convention européenne des Droits de l'Homme. Strasbourg: Council of Europe Publishing, 1997, pp. 24-25.
} 
depende mucho de la forma, el contenido y el contexto en que ocurren los hechos ${ }^{29}$.

En 2001, un ciudadano alemán Ilamado Armin Meiwes publicó en un sitio en el internet que le gustaría comerse una persona viva y que si alguien deseaba perder la vida así, entonces, debería contactarlo. Muchas personas visitaron el sitio, unas seiscientas se comunicaron y, entre ellas, sesenta fueron a conocerlo personalmente; veinte salieron con la información de que Meiwes realmente quería comerse a una persona y no en sentido figurado. Solo uno aceptó la invitación, Bernd Jürgen Armando Brandes, un ingeniero en computación de 42 años, de Berlín, a quien había conocido a través de mensajes publicados en las salas de chat.

El 9 de marzo de 2001, Meiwes y Brandes se relacionaron sexualmente. Después hicieron un rezo y planearon juntos cómo Brandes sería devorado. Así Meiwes, con el consentimiento de Brandes, primeramente amputó su pene y juntos comieron la carne humana tras freírla en una sartén, sazonada con pimienta, ajo y nuez moscada. Mientras comían, Brandes pidió a su amigo desmembrarlo solamente después de su pérdida de la conciencia por el uso de somníferos y bebidas alcohólicas. A continuación, Meiwes lo apuñaló en el cuello, seccionando la cabeza del cuerpo, colgó su cadáver en un gancho de carne y comenzó a trozarlo. Meiwes se filmó a sí mismo matando, destripando y dividiendo el cadáver de Brandes. Seguidamente, el cuerpo fue guardado en el congelador, de

29 Según lo razonado en el caso Snyder v. Phelps et al, 562 U.S. (2011). modo que Armin Meiwes se alimentó con él durante meses en sus comidas diarias, llegando a consumir alrededor de $20 \mathrm{~kg}$ del cadáver. El sabor de la carne, de acuerdo con Meiwes, era “similar a la carne de cerdo, un poco más amarga y más fuerte, pero el sabor es muy bueno" ${ }^{30}$. Cuando acabó la carne, colocó otro anuncio en el internet. En esta nueva Ilamada contaba lo ocurrido con Brandes y buscaba nuevos interesados. Finalmente, un internauta lo denunció a la policía. Meiwes fue arrestado en diciembre de 2002 y luego se transformó en una figura pública. La prensa lo llamó “El Caníbal de Rotenburg” y "El Maestro Carnicero", sus actos y los detalles escabrosos ocuparon los titulares de la prensa de todo el mundo.

Este relato extravagante hace que nos preguntemos cuál es el propósito de este estudio. Sin embargo, en este escenario atroz surgió un problema de privacidad que apunta al centro de las diferencias europeas y estadounidenses. Una compañía cinematográfica americana produjo una película de terror basada en el caso Meiwes. En Alemania se tituló Rohtenburg ${ }^{31}$, pero su nombre original en inglés fue Butterfly: A Grimm Love Story. El estreno de la película en las salas de cine estaba previsto para enero de 2006 , pero Meiwes demandó la compañía en juicio y consiguió un mandato judicial que bloqueó su

30 Disponible en <http://g1.globo.com/Noticias/Mundo/0,,MUL1515465602,00-NA+PRISAO+CANIBAL+ ALEMAO+DA+ENTREVISTA+E+DIZ+SER+NORMAL.html>. Visitado en 22/05/2012.

31 Corresponde a la unión entre las palabras "Rotenburg", el nombre de la ciudad, y "roh", que significa "crudo" en alemán. FRIEDMAN, Lawrence et Arold, Nina-Louisa. Cannibal Rights: A Note on the Modern Law of Privacy. Northwestern Interdisciplinary Law Review, vol. IV, n I, 2011, p. 237. 
proyección. Hasta el 17 de junio de 2008, el Tribunal de Frankfurt convirtió aquel mandato en decisión definitiva, prohibiendo la proyección de la película en Alemania ${ }^{32}$.

Según el Tribunal Alemán, el caso marcó el conflicto entre dos derechos fundamentales: la privacidad de Armin Meiwes frente a la libertad de expresión de la compañía productora de la película que argumentaba difundir el expresionismo artístico y el derecho del público a conocer e informarse de todos los detalles de la historia. El Tribunal optó por proteger el derecho a la vida privada. Aunque la película no utiliza el nombre del caníbal, existía un vínculo muy fuerte entre la historia de la vida real de Meiwes y la del protagonista del filme. Del mismo modo, la trama y los personajes eran idénticos a los de los hechos ocurridos. Entonces, como la ficción estaba muy cerca de la realidad, el Tribunal sostuvo que sería difícil para la audiencia distinguir la historia de la película de la de los acontecimientos reales ${ }^{33}$. Generalmente, la regla es que una persona que comete un delito como este acaba teniendo que aceptar que el público en general tiene un gran interés en el descubrimiento y conocimiento de todos los hechos. De este modo, la vida y los hechos penales son de importancia pública y, por eso, se autoriza una completa libertad en los medios de comunicación para llevar al público todo tipo de información posible. Esa es la premisa básica en los EE. UU. Sin em-

32 Olg Frankfurt am Main, fallo $n^{\circ} .14 \cup$ 146/07 17, de 17 de junio de 2008. Decisión disponible en <http://ipkitten.blogspot.com.br/2008/07/ raw-deal-for-film-producer-as-olg.html>. Visitado en 22/05/2012.

33 OLG Frankfurt am Main, fallo $n^{\circ} .14 \cup$ 146/07 17, de 17 de junio de 2008. Decisión disponible en <http://ipkitten.blogspot.com.br/2008/07/ raw-deal-for-film-producer-as-olg.html>. Visitado en 22/05/2012. bargo, en este caso concreto, el Tribunal alemán declaró que la película no servía como fuente de información pública, pues su principal objetivo era simplemente entretener a las personas que simpatizan con este género cinematográfico.

Para el derecho alemán, así como en la tradición activista europea, no había duda de que Meiwes fuera una figura pública. En este contexto, destacó el Tribunal, hay dos tipos de figuras públicas en la sociedad: aquellos que ocupan su posición en la historia contemporánea y aquellos cuya notoriedad es parcial y efímera. Así, en relación con el derecho a la vida privada, estas figuras de media notoriedad gozan de mayor protección que aquellas más famosas y significativas. La libertad de expresión es realmente un valor importante en una sociedad democrática, pero para esas figuras de media notoriedad -como Meiwes- la libertad de expresión artística no es absoluta y la película constituye una intrusión masiva en su privacidad y también representa una lesión a su personalidad. A pesar de la monstruosidad de su crimen, Meiwes sigue siendo titular de los derechos, y las leyes y la Corte tienen el deber de respetarlos.

Hasta acá no hay novedad en el entendimiento del Tribunal alemán, al final, la tradición activista europea sobrepone la dignidad de la persona y restringe el uso extrapolado de la libertad de expresión. No obstante, esta regla no tiene siempre una aplicación absoluta, y toda vez que hay una fuga de la comprensión matriz, la doctrina y la jurisprudencia europea van a buscar subsidio en el derecho estadounidense, creando un punto de intersección entre las dos escuelas jurídicas. 
Entonces, a pesar de la decisión del Tribunal de Apelación, hubo una nueva apelación ante el Tribunal Constitucional alemán que, sorprendentemente, invirtió el caso en favor de la libertad de expresión. En la decisión, la Corte Constitucional hizo hincapié en la libertad de expresión artística que, en realidad, no es absoluta, pero en este caso ella particularmente sobrepuja la privacidad y reputación de Meiwes ${ }^{34}$. Luego, se entendió que él representaba a un pequeño y enfermo grupo de personas. El deseo de comer carne humana es algo raro y eso es suficiente para estimular la curiosidad del público que no comparte ese extraño deseo y, al mismo tiempo, intenta entender cómo esto es posible. Aquí, la libertad de expresión venció la vida privada. Este giro de entendimiento fue algo muy nuevo en la cultura europea y contó ciertamente con la rica contribución de las lecciones extraídas de la experiencia americana.

Por otro lado, en los EE. UU., más precisamente en 1931, hubo un hecho muy peculiar de la tradición libertaria estadounidense. El caso Melvin v. Reid cuenta la historia de Gabrielle Darley Melvin, quien trabajó gran parte de su vida como prostituta en Los Ángeles. En un momento de desespero en su vida, ella disparó y mató a su rufián y amante, Leonard Tropp. Acusada de asesinato, fue considerada inocente por el jurado. Más adelante, salió de Los Ángeles y cambió su vida; se casó y se convirtió en un miembro respetado de su nueva ciudad. El problema se produjo cuando, años después de los acontecimientos, lanzaron la película The Red Kimono,

34 BGH, 26 de mayo de 2009, decisión nº. VI ZR 191/08. Disponible en <http://merlin.obs.coe.int/iris/2009/7/article10.en.html>. Visitado en 22/05/2012. que contaba la historia de su vida con uso de su verdadero nombre. El efecto de esta película fue desastroso en su vida social, lo que la llevó a procesar a los responsables por la violación de su vida privada.

Por la tradición libertaria estadounidense, el Estado no podía reconocer el derecho a Gabrielle Melvin a que se opusiera a la libertad de expresión de la compañía cinematográfica y su decurrente derecho de llevar a todos los ciudadanos informaciones de hechos de interés público. Entretanto, la señora Melvin, ante la justicia, afirmó que la película invadió su privacidad y la perjudicó mucho porque arruinó su reputación y respetabilidad conquistada a lo largo de los años.

Inusitadamente, ella ganó el caso y la Corte de California sostuvo que tenía derecho a una vida nueva sin ninguna invasión de su privacidad por los medios de comunicación ${ }^{35}$. Este también es un caso clásico de intersección de la tradición europea en el derecho estadounidense. A pesar de no ser la tendencia de la escuela libertaria americana, se da esta intersección en algunos votos razonados de la Suprema Corte de los EE. UU., como, por ejemplo, en el caso Olmstead v. United States (1929), en el que el juez Brandeis argumentó que el derecho de ser dejado solo es el más comprensible de los derechos y lo más valorado por hombres civilizados ${ }^{36}$.

35 Melvin v. Reid, 112 Cal. App. 285, 297 Pac. 91 (1931), en Lewis, Anthony. Freedom for Thought that we Hate: a biography of the first amendment. New York: MJF Books, 2007, p. 73.

36 Hall, Kermit L. The Oxford Companion to American Law. New York: Oxford University Press, 2002, p. 637. 
A pesar de la brillante conclusión, este fallo fue abandonado y hoy este precedente no tiene ninguna fuerza. La cultura jurídica americana no admite la prohibición de una publicación de hechos que, de cierto modo, ya son públicos. Como se ha dicho en el juicio de Sidis, una vez que alguien se somete a la atención del público ya no puede escapar de esta condición. Pero esto deja lugar a dudas sobre hasta qué punto puede un periodista sensacionalista entrometerse en la vida privada. La decisión en el caso Melvin marcó la historia de la jurisprudencia de los EE.UU. por su extrañeza, ya que está totalmente fuera de la línea interpretativa del juicio de ponderación entre la privacidad y la libertad de expresión. E resultado final de este caso fue y es algo nuevo y sorprendente, que ciertamente contó con las lecciones y las experiencias culturales europeas que, de alguna manera, influyeron en ese evento específico. Sin embargo, muchos juristas creen que si el caso hubiera ocurrido hoy, el resultado sería completamente diferente, pero, aun así, tenemos aquí un buen punto de intersección entre las dos culturas jurídicas ${ }^{37}$.

Aunque prepondere en la tradición norteamericana el abstencionismo estatal en la libertad de expresión, hay algunas hipótesis de intersección con la tradición europea que, de cierta manera, se solidificaron en la cultura jurídica de los EE. UU. Así, en los casos que retratan expresiones de obscenidades, difamaciones, discurso apologético del odio (fighting words y hate speech), incitaciones ilegales, pornografía infantil y amenazas, el gobierno tiene el poder-deber de interferir

37 Friedman, Lawrence et Arold, Nina-Louisa. Cannibal Rights: A Note on the Modern Law of Privacy. Northwestern Interdisciplinary Law Review, vol. IV, n I, 2011, p. 239 -posición activista- pues son considerados por la dinámica jurisprudencial como contravalores nocivos al valor mayor: la libertad. En consonancia con lo explicado en el caso United States v. Álvarez, 567 U. S. (2012), estos contravalores son llamados content-based restrictions, o sea, las restricciones ya indiscutiblemente aceptadas y absorbidas por las leyes y jurisprudencia estadounidense, donde la tradición europea fue trasplantada con éxito.

\section{LA JURISPRUDENCIA DE LA CORTE INTERAMERICANA DE DERECHOS HUMANOS}

Entonces, ¿qué entiende la Corte Interamericana de Derechos Humanos de todo eso?, ¿cuál es su afinidad jurídica?, ¿sigue la tradición activista europea o la libertaria estadounidense?

En el caso Fontevecchia e D'Amico v. Argentina, juzgado por la Corte Interamericana de Derechos Humanos el 29 de noviembre de 2011, se discutió la violación de la libertad de expresión de Jorge Fontevecchia y Héctor D’Amico, director y editor, respectivamente, de la Revista Noticias. Ellos fueron condenados por la justicia argentina por haber publicado un informe invasivo de la vida privada del Presidente de la época, Carlos Saúl Menem. Se trató de dos informes publicados en 1995, que hablaban de la existencia de Carlos Nair, un hijo no registrado de Menem con Martha Meza, una parlamentaria de su Partido.

Menem, en el momento de la publicación, estaba en su segundo mandato presidencial y de- 
mandó a la Revista y a los dos periodistas por violación de su vida privada. En julio de 1997, la sentencia de primer grado juzgó infundada la reclamación de Menem, quien entonces apeló al Tribunal. En marzo de 1998, la segunda instancia invirtió el juzgado por la mayoría, condenando a la Revista Noticias y a sus dos periodistas por violación del derecho a la privacidad. A continuación, los condenados apelaron a la Corte Suprema que, en septiembre de 2001, confirmó la condena. En su decisión, afirmó que no importaba la veracidad de la noticia difundida, sino su naturaleza personal y privada. Al sopesar la tensión entre la privacidad y la libertad de expresión, la Corte Suprema sostuvo:

En el caso de las celebridades o de personas populares cuyas vidas son públicas, sus vidas pública o privada pueden ser invadidas cuando la información se refiere a la actividad por la cual ganó notoriedad y prestigio, y también cuando lo justifique el interés público. Pero el desarrollo de la vida privada no permite el daño a la imagen pública y al honor de estas personas y mucho menos para sostener que ellos no tienen privacidad inmune de interferencias [...]. La persona pública conoce las restricciones de su esfera de privacidad debida a su exposición pública relativa al ejercicio de sus funciones, pero aun así tiene el derecho a conservar una zona de paz y secretos de su vida personal. Eso es esencial para todos los hombres mientras los aspectos privados no estén relacionados con su gestión de los asuntos públicos o de intereses en la defensa de la sociedad ${ }^{38}$.

Así, planteó que la publicación de los periodistas representaba una intromisión en los asuntos ín-

38 Caso Fontevecchia e D'Amico v. Argentina, juzgado el 29 de noviembre de 2011, párrafo 39. timos de la familia y la vida privada de Menem, y que eso no se correspondía con los intereses de la comunidad, especialmente cuando implicaba la exposición de la imagen y el nombre de un menor de edad. La condena de Jorge Fontevecchia y Héctor D'Amico estuvo basada en las restricciones a la libertad de expresión estatuidas en el artículo 19 de la Constitución de la Nación Argentina $^{39}$, el artículo 1071 del Código Civil de la República Argentina ${ }^{40}$ y el artículo 13.2, "a”, de la Convención Americana sobre Derechos Humanos $^{41}$, que restringen la expresión cuando es invasiva y ofensiva del derecho a la reputación de las personas. De esta mezcla normativa, la justicia argentina optó por el predominio de la protección de la vida privada del expresidente Menem.

La cuestión central planteada por la Corte Interamericana de Derechos Humanos, entonces, fue si la sociedad argentina tenía derecho a obtener la información publicada (la dimensión objetiva del derecho) y, por tanto, la libertad de expresión prevalecería o, al contrario, si el ex

39 Artículo 19.- Las acciones privadas de los hombres que de ningún modo ofendan al orden y a la moral pública, ni perjudiquen a un tercero, están sólo reservadas a Dios, y exentas de la autoridad de los magistrados. Ningún habitante de la Nación será obligado a hacer lo que no manda la ley, ni privado de lo que ella no prohíbe.

40 Art.1071 bis.- El que arbitrariamente se entrometiere en la vida ajena, publicando retratos, difundiendo correspondencia, mortificando a otros en sus costumbres o sentimientos, o perturbando de cualquier modo su intimidad, y el hecho no fuere un delito penal, será obligado a cesar en tales actividades, si antes no hubieren cesado, y a pagar una indemnización que fijará equitativamente el juez, de acuerdo con las circunstancias; además, podrá éste, a pedido del agraviado, ordenar la publicación de la sentencia en un diario o periódico del lugar, si esta medida fuese procedente para una adecuada reparación.

41 13.2.El ejercicio del derecho previsto en el inciso precedente no puede estar sujeto a previa censura sino a responsabilidades ulteriores, las que deben estar expresamente fijadas por la ley y ser necesarias para asegurar: a) el respeto a los derechos o a la reputación de los demás. 
Presidente de Argentina tenía la prerrogativa de mantener el secreto sobre la información revelada. Luego las premisas iniciales apuntan a las dos tradiciones estudiadas. ¿Debe prevalecer el derecho de información y a la información con total abstención del Estado, porque el expresionismo es una fuente de libertad y las figuras públicas no tienen expectativa razonable a su privacidad? 0 ¿debe prevalecer la dignidad humana de la persona cuya vida fue invadida, con acción represiva del Estado para cohibir el ejercicio abusivo de la libertad de expresión?

En segundo plano, se puede aún preguntar: ¿hasta dónde va la protección de la vida privada de una figura pública, sobretodo si se trata de la autoridad máxima del Estado cuyo comportamiento se somete al escrutinio más rigoroso de la sociedad? Con eso, la Corte comienza el desarrollo del entendimiento de que a pesar de la libertad de expresión y la vida privada estar ambos reglados en la Convención Americana sobre Derechos Humanos, el primero no es absoluto y el segundo se reduce en la medida que la importancia de las acciones y funciones ejercidas por la persona tengan el carácter de interés general, en una sociedad democrática.

Como observa Urioste Braga, la protección de la honra y de la dignidad y el reconocimiento de la libertad de expresión no casualmente están legislados juntamente en la Convención Americana sobre Derechos Humanos (art. 11 hasta 13). Al final, la divulgación de información privada puede estar vinculada, y ocurre casi siempre, con situaciones que menoscaban el honor de la persona atacada. Entretanto, cabe preguntarse si es legítimo difundir la vida privada de los gobernantes. La respuesta, dice él, depende de los valores culturales de cada sociedad, valores estos expresados a través de las creencias o convicciones arraigadas en una comunidad, en usos, costumbres y normas jurídicas que establecen el límite de lo lícito. Luego, no hay un criterio único aceptado como correcto ${ }^{42}$.

Para una sociedad como la de los EE. UU., es legítimo discutir y descubrir la vida privada de las personas públicas porque existe un derecho de todos los miembros de la sociedad de conocer las virtudes y defectos morales de quienes se postulan para cargos públicos. En consecuencia, la moral privada es considerada una virtud que influye en las tareas de gobierno. Para la sociedad europea, la vida privada de la figura pública debe quedarse fuera de todo escrutinio público porque es una información que no agrega nada sustantivo a la calidad de buen funcionario público y tampoco garantiza una buena gestión.

A pesar de esto, la Corte, en el razonamiento del caso Fontevecchia e D'Amico v. Argentina, camina por su jurisprudencia que es pacífica en decir que todas las personas que están bajo el manto protector de la Convención no solo tienen el derecho a buscar, recibir y difundir informaciones e ideas sobre cualquier asunto, sino también tienen el derecho de recibir informaciones y ser informadas acerca de las ideas y asuntos difundidos por los demás -tradición estadounidense-. La restricción de la libertad de expresión nunca debe llegar más allá de lo estrictamente

42 Braga, Fernando Urioste. Libertad de expresión y derechos humanos. Buenos Aires, Argentina: Editorial IBdeF, 2008, p. 181. 
necesario, pues puede convertirse en un mecanismo directo o indirecto de censura, luego parte de un campo amplio de acción libertaria ${ }^{43}$. Por eso los medios de comunicación asumen un papel clave en el desarrollo de la dimensión social de la libertad de expresión en una sociedad democrática: derecho de información y a la información. Este papel vital pone la prensa como correspondiente en la función social de reunir la mayor cantidad de informaciones y diversidad de opiniones posibles ${ }^{44}$.

Es así como en todos los casos en que hay un conflicto entre la libertad de expresión y la vida privada, la Corte ejerce un juicio de ponderación sobre el choque de los dos derechos fundamentales garantizados por la Convención, ambos esenciales para una sociedad democrática. Todo derecho fundamental, por lo tanto, debe ser ejercido en consideración de otros derechos fundamentales. Sus coexistencias representan un proceso de armonización en que el Estado tiene la importante función de determinar las responsabilidades e imponer las sanciones necesarias para lograr el equilibrio. De ese modo, el Estado debe minimizar las restricciones a la difusión de información en el campo de las comunicaciones sociales, permitiendo el debate colectivo de amplia participación sobre los diferentes tipos de asuntos. Ese es el postulado y estímulo del pluralismo informativo ${ }^{45}$.

43 Caso Tristán Donoso v. Panamá, juzgado el 27 de enero de 2009, párrafos 109 y 110.

44 fo 117

45

Caso Kimel v. Argentina, juzgado el 2 de mayo de 2008, párrafo 57 hasta 75.
En análisis a los argumentos de la Corte Suprema de Justicia de Argentina que condenó a los periodistas, la Corte Interamericana de Derechos Humanos revirtió la condena de los periodistas y de la Revista apuntando las siguientes observaciones: a) a pesar de la legalidad de la medida, la restricción dada a la libertad fue contraria al derecho; aunque el Código Civil argentino sea ley en sentido formal, no lo es en sentido material porque la ley restrictiva no puede contener imprecisiones o vaguedad, ya que confiere una carga muy alta de discrecionalidad en la interpretación de los méritos y reparaciones (tal cual el precedente Olmedo Bustos y otros vs. Chile, de 2001, conocido en la Corte como el caso "La última tentación de Cristo"); y b) se tiene como dudosa la necesidad de restricciones en la libertad de expresión, al final la información publicada era de interés público e implicaba, entre otras cosas, la existencia de un niño no reconocido por el ex Presidente y este comportamiento se relaciona con las obligaciones morales y legales de cualquier persona.

En la primera observación, la Corte acoge la doctrina americana de supremacía de la libertad de expresión, inclusive sobre las leyes del país (pues la tradición estadounidense es la libertad en oposición al Estado, sea el Poder Ejecutivo o el Poder Legislativo), cuyo contenido debe ser específico y puntual en cuanto a sus restricciones de libertad. La prohibición es la vaguedad de la norma restrictiva porque si la restricción es imprecisa, la propia esencia de la libertad queda vulnerable. Las personas que no quieren actuar fuera del ámbito de la ley afrontarán una serie de abstenciones de comportamiento que 
suponen estar dentro del marco genérico prohibitivo, así, para evitar el riesgo de la ilegalidad y el sometimiento a sus consecuencias, se alejarán de cualquier conducta que pueda ser incorporada en la incertidumbre de la ley. Por eso se dice que los efectos de la ley exceden la permisión de hacer restricciones en esta libertad, establecidas en las Declaraciones de Derechos Humanos $^{46}$. Luego la vaguedad en las restricciones de la libertad de expresión no solo reduce el contenido de la libertad sino que también infringe la tolerancia de la norma permisiva.

En un segundo momento, la Corte acoge aqueIlo que Carlos Fayt Ilama doctrina de la Real Malicia ${ }^{47}$, que trata de la adopción del derecho de información y a la información derivado de la doctrina establecida por la Suprema Corte de los EE. UU., en el caso New York Times Co. v. Sullivan, 376 US 254 (1964). El leading case trata de la lucha por los derechos civiles de los negros, y el diario, en 1960, publicó un artículo que, sin decir nombres, anunciaba "Ios sudistas transgresores de la Constitución”, y un policial sudista llamado L. B. Sullivan procesó el diario por calumnia y difamación. El asunto llegó ante la Suprema Corte de los EE. UU. que juzgó el caso como un tema de relevancia pública, que merecería profundo análisis y debates abiertos. Con ello, estableció las premisas madisonia-

46 Esta doctrina de la prohibición de la vaguedad de las normas se origina en los casos Broadrick v. Oklahoma, 413 U.S. 601 (1973) y Board of Trustees of State Univ. of N.Y. v. Fox, 492 U.S. 469, 483 (1989). En la Corte Interamericana de Derechos Humanos la doctrina fue acogida en el caso "La última tentación de Cristo" - Olmedo Bustos y otros vs. Chile, juzgado el 5 de febrero de 2001.

47

FAYT, Carlos S. La Corte Suprema y la evolución de su jurisprudencia: Leading cases y holdings - casos trascendentes. Buenos Aires, Argentina: La Ley, 2004, p. 213. nas $^{48}$, de que la responsabilidad sobre cualquier criticismo en este espacio solo podría prosperar si la víctima comprobaba debidamente la falsedad de su contenido, si no la noticia sigue inamovible y verídica. Al final este tipo de crítica periodística fortalece la democracia.

La doctrina de la Real Malicia, por lo tanto, concede amparo a las publicaciones difamatorias cuando la información acerca de la personaobjeto es de interés público, sobre todo si se trata de funcionario público, cuyo control de su actuación pertenece a la sociedad. De acuerdo con lo establecido en el precedente New York Times Co. v. Sullivan, el falso pronunciamiento no es contrario a la libertad de expresión, a menos que sea consciente e irresponsablemente falso o inexacto. De esta manera, procura evitar la autocensura. No se trata aquí de buscar la "verdad absoluta, sino de buscar leal y honradamente lo verdadero, lo cierto, lo más imparcialmente posible y de buena fe" ${ }^{49}$. La relación de tensión permanente que pretende resolver esta doctrina es la que existe entre el derecho a la dignidad personal y el derecho de información -justamente las vertientes tradicionales esta-

48 James Madison es considerado el padre del Bill of Rights de la Constitución, por cuanto él amonestaba al Parlamento de Virginia con respecto a que la libertad de expresión y prensa son esenciales al sistema político republicano porque conceden el derecho de libremente examinar los comportamientos y conductas políticas y medidas públicas adoptadas por los gobernantes. Así, creó la idea de la no interferencia estatal en la prensa, mismo si la noticia es falsa, donde se pueden suceder solo las responsabilidades, civiles o penales, ulteriores. Luego, el Estado no frena un diario que tiene el deber de criticar las políticas gubernamentales. Este discurso de Madison, en la segunda mitad del siglo XVIII, fue conocido como las premisas madisonianas. LEWIS, Anthony. Freedom for Thought that we Hate: a biography of the first amendment. New York: MJF Books, 2007, p. 18.

FAYT, Carlos S. La Corte Suprema y la evolución de su jurisprudencia: leading cases y holdings - casos trascendentes. Buenos Aires, Argentina: La Ley, 2004, p. 214. 
dounidense y europea-, pues exime de responsabilidad al periodista por las lesiones, daños o perjuicios causados, excepto si el ofendido logra probar que las informaciones son inexactas o falsas.

Entonces, el acogerse a la doctrina de la Real Malicia absorbe sustancialmente la tradición libertaria norteamericana, del uso amplio y raramente restricto de la libertad de expresión. Se parte del comportamiento negativo del Estado como regla general -la abstención-. Pero la Corte Interamericana no adopta la tradición libertaria norteamericana de forma absoluta. En verdad, se vale también de las contribuciones excepcionales de la tradición activista europea, donde la dignidad de la persona se sobrepone a la libertad, aunque sea su aplicación residual.

En la segunda observación, la Corte destaca la doctrina europea del predominio de la dignidad humana, suprema inclusive para los medios de comunicación. Entretanto, aquí debemos tener en cuenta los detalles construidos en la jurisprudencia a lo largo del tiempo con respecto a las figuras públicas. En este caso, así como en otros de esta Corte, reina el entendimiento de que en una sociedad democrática, las personas públicas del ámbito político están más expuestas al escrutinio y la crítica del público, en consonancia con la doctrina de la Real Malicia y los precedentes norteamericanos.

Este origen diferenciado de protección -figura pública y no pública- se debe al hecho de que las personas públicas voluntariamente se exponen al escrutinio estricto. Sus acciones van más allá de la esfera privada y entran en el mundo del debate público. Esta reducción de la protección no se basa únicamente en la naturaleza del individuo, sino también en el interés público ínsito en su desempeño. No hay duda en que el artículo 11 de la Convención Americana da a cada uno el derecho a la vida privada y prohíbe toda injerencia arbitraria o abusiva en la privacidad de las personas, como la familia, el hogar y la correspondencia ${ }^{50}$. No obstante, la Corte hizo una reverencia a la tradición europea, pues al aplicar la doctrina de la Real Malicia se cuidó de motivar puntualmente su excepcionalidad y ejercer el juicio de ponderación judicial en relación con la persona afectada - figura pública de máxima notoriedad en el gobierno argentino-y la naturaleza de la información difundida, cuyo contenido era de interés público y no mero entretenimiento, pues la postura moral del Presidente no es algo trivial.

La Corte expresamente fundamenta su razonamiento y juicio de ponderación entre la libertad de expresión y la vida privada de Menem, acudiendo al caso Von Hannover v. Germany, juzgado por la Corte Europea de Derechos Humanos en 2004. Establece que el art. 11.2 de la Convención Americana protege al individuo de la interferencia arbitraria o abusiva del Estado, pero no impone de este solamente un comportamiento negativo - non facere-, sino también, como lo expresa el art. 11.3, un comportamiento positivo -facere-, tornando prohibida la mera inhibición de acción y obligatoria la postura estatal de adopción de medidas que aseguren la privacidad contra intervenciones de autorida-

50 Caso Tristán Donoso v. Panamá, juzgado el 27 de enero de 2009, párrafos 55 hasta 115. 
des públicas o instituciones privadas, inclusive la prensa ${ }^{51}$. Hay, por lo tanto, un abordaje de las dos tradiciones jurídicas, la estadounidense y la europea, aunque la aplicación predominante pertenece a la primera.

\section{CONCLUSIÓN}

El estudio comparado de la jurisprudencia, sobretodo de la jurisprudencia internacional sobre derechos humanos, realza los rasgos culturales de los pueblos al mismo tiempo que demuestra la madurez y la evolución de las soluciones jurídicas dadas a los litigios sociales diuturnos. Entre muchas vicisitudes de carácter existencialista relacionadas con los derechos humanos, elegimos el choque entre dos derechos: la libertad de expresión -de línea democrática, que promueve la participación ciudadana en el proceso político del Estado y el pluralismo en la difusión y recepción de informaciones, opiniones e ideas diversas en la colectividad-y la vida privada - que reconoce a cada uno, individualmente, el recato, la intimidad y el sosiego, oponibles contra todos.

En este sentido, la jurisprudencia de Europa y de los EE. UU. produce una serie de precedentes que guían prácticamente todos los demás tribunales en sus posicionamientos. Por lo tanto, en los sistemas jurídicos complejos, donde se tiene una gran variedad de derechos y garantías, es natural la ocurrencia de un eventual conflicto

51 Corte Europea de Derechos Humanos, caso Schussel v. Austria, juzgado el 21 de febrero de 2002, párrafo 02; Von Hannover v. Germany, juzgado el 24 de junio de 2004, párrafo 57; también en el art. 12 de la Resolución 1165, de 26 de junio de 1998, del Council of Europe Parliamentary Assembly sobre el derecho a la vida privada. entre ellos. Así, un tema delicado y controvertido es el juego de ponderación entre el derecho a la vida privada y la libertad de expresión, en el que Europa y los EE.UU. tienen muy bien definidos los criterios de prevalencia y ablandamiento en su aplicación. Mientras la tradición europea hace una aplicación más activista y preferente de la vida privada, en homenaje a la dignidad de la persona, la tradición estadounidense opta por la aplicación libertaria y preferente de la libertad de expresión, considerando carga de la democracia eventuales ataques a la vida privada.

En esta línea, la Corte Interamericana de Derechos Humanos, en la construcción de su propia jurisprudencia, extrae lo mejor de los dos mundos. La Corte, en sintonía con el derecho moderno, parte de la premisa de que todo derecho jurídicamente garantizado es igualmente limitado y, con eso, ningún derecho es absoluto, al contrario, todos son susceptibles de relativización. De ahí que ha aceptado el predominio de la libertad de expresión sustentada en la visión libertaria de la tradición norteamericana, mientras con la aplicación residual del activismo preconizado en la tradición europea respecto a la acción del Estado va en socorro de la dignidad humana y la incolumidad de la vida privada.

Cuando hay un conflicto entre la libertad de expresión y la vida privada - como se ha visto en el caso Fontevecchia e D’Amico v. Argentina, referenciado en los casos Tristán Donoso v. Panamá; Kimel v. Argentina y Herrera Ulloa v. Costa Rica-, la Corte Interamericana de Derechos Humanos siempre hace un juicio de ponderación. La coexistencia entre ellos es el producto final 
de este juicio que se pauta en un proceso de armonización en el que el Estado tiene la importante función de determinar las responsabilidades e imponer las sanciones necesarias para lograr el equilibrio.

De ese modo, es acogida de manera sobresaliente la doctrina libertaria norteamericana de supremacía de la libertad de expresión. Esto ocurre, tanto cuando los actos estatales y las leyes trabajan con la vaguedad normativa como medio de control y contención de comportamiento humano como cuando la divulgación periodística de informaciones sobre figuras públicas atenta contra la vida privada de estas. No hay duda de que la Corte Interamericana eligió la tradición libertaria de la abstención del Estado y la difusión prácticamente plena de la libertad de expresión. Este es el norte de solución de los conflictos que involucran la libertad democrática y el derecho social de información y a la información.

No obstante, es cierto que la libertad de expresión no es absoluta y que comporta restricciones, pero esas, en nombre del principio democrático, deben ser específicas y puntuales, jamás genéricas y abiertas -en consonancia con la tradición estadounidense, content-based restrictions-, e individualmente definidas para no olvidarse de su carácter de excepcionalidad. Igualmente, el continente americano tiene las puntuales restricciones de la Convención Americana (art. 11) y su jurisprudencia, inclusive con la adopción de la doctrina de la Real Malicia. Por tanto, sigue siendo válida la regla general de que todos los Estados democráticos de derecho de la América deben al máximo minimizar las restricciones a la difusión de información en el campo de las comunicaciones sociales, permitiendo el debate colectivo de amplia participación sobre los diferentes tipos de asuntos. Ese es el compromiso y estímulo del pluralismo informativo.

Aunque la información difundida sea de contenido privado de la figura pública, se parte de la presunción -juris tantum- de que la divulgación es válida y necesaria para la democracia y el pluralismo de opiniones. La regla general adoptada - de tradición norteamericana- es que toda figura pública debe soportar la invasión de su vida privada, pues voluntariamente aceptó ingresar en la vida pública, sin expectativa razonable de privacidad (reasonable expectation of privacy) $y$, en esa medida, todo tipo de información producida es válida, inclusive la falsa o inexacta - premisa madisoniana-. El falso pronunciamiento, en este particular, no es contrario a la libertad de expresión, a menos que sea consciente e irresponsablemente falso o inexacto, en cuyo caso la responsabilidad del periodista por las lesiones, daños o perjuicios causados ocurrirá si el ofendido lograr probar que las informaciones son inexactas o falsas.

En este punto, el caso Fontevecchia e D'Amico $v$. Argentina demostró con precisión este entendimiento, al decir que "se tiene como dudosa la necesidad de restricciones en la libertad de expresión, al final la información publicada era de interés público". Luego, no logró el ofendido probar la inexactitud o falsedad de la publicación del diario, lo que de por sí aparta la caracterización de uso arbitrario o abusivo de la libertad de expresión. Por eso, no cabe hablar 
de responsabilidad de los periodistas por ejercer sus libertades.

Además, la Corte Interamericana fue elocuente al ir más allá de su razonamiento y traer a la discusión, fuera del debate sobre falsedad o inexactitud, el de la dignidad de la persona y el conflicto entre el interés público y el núcleo inalcanzable de la vida privada. Esta posición, a su vez, es un homenaje residual (punto de intersección entre las dos culturas) a la tradición europea que recomienda la intervención estatal para salvaguardar la dignidad humana y, concomitantemente, inhibir y cohibir el ejercicio abusivo de la libertad de expresión. Esta libertad es realmente fundamental a los Estados, no hay dudas, pero no se puede dejar de lado el respeto a la incolumidad de la vida privada de las personas. La reverencia al respeto de la vida privada de las personas solamente tolera restricción -en el sentido de divulgación de actos privados- cuando está relacionada con figuras públicas y, aun así, si la naturaleza de la información que se desea difundir es de interés público y no mero entretenimiento.

Es cierto que el juicio de ponderación necesario en situaciones de conflicto entre derechos fundamentales Ileva consigo una carga de subjetivismo de los juzgadores, lo que acaba desafiando el derecho en cuanto a la primacía mayor de que las reglas deben ser las mismas para todos. Sin embargo, como ciencia de conexión social, el derecho es muy sensible a los detalles y a la presencia o ausencia de ellos, lo que acaba por generar un producto final diferente, avalado por los criterios del contenido, la forma y el contexto de las situaciones planteadas. No obstante, la Corte Interamericana de Derechos Humanos ha definido con claridad su tendencia casi total hacia la tradición estadounidense en cuanto a la libertad de expresión, en la que el Estado es primordialmente abstencionista y raramente activista, aun cuando tal libertad colisione con el derecho individual de la vida privada.

Las tradiciones jurídicas europeas y estadounidenses demuestran muy claramente la tendencia de sus entendimientos y orientaciones, sin descartar, obviamente, los puntos de intersección donde el resultado final termina siguiendo una ruta diversa. Esta ductilidad, sin embargo, hace del derecho un organismo vivo, estable sin ser estático y dinámico sin ser frenético, permitiendo en cada caso un cambio de la comprensión de acuerdo con las circunstancias presentadas (contenido, forma y contexto). En este sentido, entonces, la Corte Interamericana de Derechos Humanos puede trabajar con mayor tranquilidad, ya que, de antemano, añade, protege y refuerza la densidad jurídica compartida de las dos tradiciones y culturas jurídicas rectoras, tanto en su perfil libertario como activista.

\section{Bibliografía}

Anderson, David A. The Failure of American Privacy Law. In Protecting Privacy, Basil S. Markesinis ed., 1999.

Braga, Fernando Urioste. Libertad de expresión y derechos humanos. Buenos Aires, Argentina: Editorial IBdeF, 2008.

Cato - Center for Constitutional Studies. Supreme Court Review 2006-2007. Washington, DC: CATO, 2007. 
Corte Interamericana de Derechos Humanos. Memoria del seminario El Sistema Interamericano de Protección de los Derechos Humanos en el umbral del siglo XXI. Tomo I. $2^{a}$ edición. San José, CR: Corte Interamericana de Derechos Humanos, 2003.

Counseil de L'eURope, ECHR. La liberté d'expression en Europe - Jurisprudence relative à l'article 10 de la Convention européenne des Droits de l'Homme. Strasbourg: Council of Europe Publishing, 2007.

Fayt, Carlos S. La Corte Suprema y la evolución de su jurisprudencia: Leading cases y holdings - casos trascendentes. Buenos Aires, Argentina: La Ley, 2004.

FIss, Owen M. The Irony of Free Speech. Cambridge, Massachusetts: Harvard University Press, 1996.

Friedman, Lawrence et Arold, Nina-Louisa. Cannibal Rights: A Note on the Modern Law of Privacy. Northwestern Interdisciplinary Law Review, vol. IV, n. I, 2011, pp. 235-246.

García Ramírez, Sergio y Gonza, Alejandra. La libertad de expresión en la jurisprudencia de la Corte Interamericana de Derechos Humanos. San José, CR: Corte Interamericana de Derechos Humanos, 2007.

GIFIS, Steven H. Law Dictionary. $5^{\mathrm{a}}$ edition. New York: Barron's Educational Series, 2003.

Godoy, Arnaldo Sampaio de Moraes. Direito nos Estados Unidos. Barueri: Manole, 2004.
GreER, Steven. Les exceptions aux articles 8 à 11 de la Convention Européenne des Droits de l'Homme. Strasbourg: Council of Europe Publishing, 1997.

Hall, Kermit L. The Oxford Companion to American Law. New York: Oxford University Press, 2002.

- The Oxford Companion to the Supreme Court of the United States. $2^{a}$ edition. New York: Oxford University Press, 2005.

Kluwer, Wolters. Constitutional Law: Casenote Legal Briefs. $16^{a}$ edition. New York: Aspen Publishers, 2008.

LeWIS, Anthony. Freedom for Thought that we Hate: a biography of the first amendment. New York: MJF Books, 2007.

Macovel, Monica. Freedom of Expression: A guide to the implementation of Article 10 of the European Convention on Human Rights. $2^{\text {nd }}$ Edition. Strasbourg: Council of Europe Publishing, 2004.

Rabinovich-Berkman, Ricardo. Derechos humanos: una introducción a su naturaleza y a su historia. Buenos Aires: Quorum, 2007.

SARMENTO, Daniel. Livres e Iguais: Estudos de Direito Constitucional. Rio de Janeiro: Lumen Juris, 2006.

Schwabe, Jürgen (org.). Cinquenta anos de jurisprudência do Tribunal Constitucional Federal Alemão. Montevideo, Uruguay: Fundación Konrad-Adenauer-Stiftung E. V., 2005. 
Strahilevitz, Lior Jacob. A Social Networks Theory of Privacy. In Chicago John M. Olin Law \& Economics Working Paper $n^{\circ} 230$ ( $2^{\text {nd }}$ series), November 2004.

Tolzer, Fernando M. El formalismo en la libertad de expresión: crítica de la distinción absoluta entre restricciones previas y responsabilidades ulteriores. Buenos Aires: Marcial Pons Argentina, 2011.
WhitMAn, James Q. Enforcing Civility and Respect: Three Societies. The Yale Law Journal, vol. 109:1280, 2000.

The Two Western Cultures of Privacy: Dignity versus Liberty. The Yale Law Journal, vol. 113:1151, 2004. 